\title{
In vitro Senescence of Human Keratinocyte Cultures
}

\author{
G.A. Rockwell, G. Johnson and A. Sibatani* \\ CSIRO Division of Molecular Biology, P.O. Box 184, North Ryde, NSW 2113, \\ Australia
}

\begin{abstract}
Human keratinocytes have been serially cultivated in low $(0.015 \mathrm{mM})$ and high $(1.8 \mathrm{mM})$ calcium containing medium. The calcium concentration of the growth medium significantly influenced the cell growth period in vitro. Cells grown in low calcium medium underwent 35-40 population doublings over 16-17 passages, while cells grown in high calcium medium ceased to proliferate after 20 population doublings over 7 passages. Changing the keratinocytes from one in vitro environment to the other drastically altered the lifespan in culture of populations derived from the same primary tissue. The degree of DNA methylation of human keratinocytes was shown to decrease with age in both high and low calcium culture conditions but does not appear to be associated with differentiation.
\end{abstract}

Most of the studies on the ageing of cells in vitro have been performed on mammalian diploid fibroblasts. These cells, as is well known, have a finite capacity to multiply in culture and eventually undergo senescence. This limitation of the proliferative potential, which is determined by the number of cell divisions and is independent of the chronological age of the culture, has led to the use of these cells as models for cellular ageing (10). The mechanism by which this phenomenon takes place in cells is unknown and into this void have come several hypotheses to explain cellular senescence in vitro and to relate this phenomenon to in vivo ageing $(1,16$, $17,19,25)$. The literature on fibroblast senescence in vitro and its possible causes has recently been reviewed $(12,13)$.

We have turned our attention to the human keratinocyte culture system which, although more complex, offers significant advantages over the fibroblast system. Human keratinocytes in vitro undergo terminal differentiation, a property which if not totally absent in the fibroblast, is at the very least, obscure. Moreover the differentiation of cultured keratinocytes can be experimentally manipulated by the extracellular calcium concentration in the growth medium (11). In high calcium $(>0.1 \mathrm{mM})$ medium human keratinocytes differentiate whereas in low calcium $(<0.1 \mathrm{mM})$ medium the cells are prevented from differentiating and are maintained in the stem cell configuration (23). The differentiation in vitro however is not identical to that which occurs in vivo. Fuchs and Green (8) have demonstrated differences in the keratin pattern of cells grown in vitro compared to in vivo skin whilst the keratin patterns of cells grown in either high or low calcium containing growth medium in vitro is the same (3). This culture system then offers the advantage of undergoing terminal differentiation which can be measured and experimentally manipulated and

* Present address: Kansai Medical University, Uyamahigashi, Hirakata 573, Japan. 
which approximates very closely the situation in vivo.

Several reports have indicated changes in cellular DNA with ageing of cells in culture $(24,29,31,32,35,36)$. More specifically a decrease in hybridisable ribosomal DNA has been demonstrated with age in human heart (31) and brain tissue (32). Shmookler Reis' laboratory has recently shown, both in vitro and in vivo, an increase in extrachromosomal inter-alu circular DNA molecules (29). Wilson and Jones (36) have reported decreases in the levels of DNA methylation occurring with time in culture of diploid mouse cells in contrast to the situation with immortal cell lines. Romanov and Vanyushin (23) have demonstrated decreases in the methylation of reiterated DNA sequences in cattle with ageing but not in unique sequences. These results would tend to indicate a degree of instability of the cell genome with time or cell division; however, Erlich et al. (6) have failed to detect any differences in the 5 methyl cytosine content of tissues from young and aged humans or in cultured human fibroblasts subdivided and allowed to grow over a period of 5 weeks compared to cultures maintained at confluence for the same period of time.

In this report we demonstrate that:

i) the calcium concentration of the growth medium significantly influences the cell growth period in vitro. Human keratinocyte cultures under high calcium growth conditions cease proliferation sooner than cultures grown under low calcium growth conditions,

ii) the fate of cell populations can be reversed by changing the growth conditions and,

iii) the degree of DNA methylation of human keratinocytes decreases with age in culture but does not appear to be related to differentiation.

\section{MATERIALS AND METHODS}

Growth of cells. Human keratinocytes were derived from neonatal human foreskin and grown on irradiated fibroblast feeder layers according to Rheinwald and Green (22). During primary culture the cells were grown in Dulbecco's modified Eagle's medium (DME) containing penicillin $(200 \mathrm{U} / \mathrm{ml})$, streptomycin $(100 \mu \mathrm{g} / \mathrm{ml})$ and sodium bicarbonate $(3.6 \mathrm{~g} / \mathrm{l})$ supplemented with $10 \%$ foetal calf serum, cholera toxin $(10 \mathrm{ng} / \mathrm{ml})$, hydrocortisone $(10 \mu \mathrm{g} / \mathrm{ml})$ and epidermal growth factor $(10 \mathrm{ng} / \mathrm{ml})$. After the first passage, cells were grown on irradiated fibroblast feeder layers in medium as above (high calcium) or in a $1: 1(\mathrm{v} / \mathrm{v})$ mixture of calcium free DME and Ham's MCDB 151 (20) containing the additions indicated above except that foetal calf serum was replaced with chelex treated foetal calf serum (low calcium). The calcium concentration, determined by atomic absorption, for whole serum was $3.49 \mathrm{mM}$ whilst for chelex treated serum, $0.01 \mathrm{mM}$. These sera were added at $10 \%$ to DME (1.82 $\left.\mathrm{mM} \mathrm{Ca}^{++}\right)$and calcium free DME/MCDB151 (0.015 $\left.\mathrm{mM} \mathrm{Ca}^{++}\right)$respectively.

At passage, cells were routinely washed with $0.02 \%$ EDTA in PBS to remove fibroblasts. The attached cells were harvested with $0.2 \%$ trypsin- $0.02 \%$ EDTA in PBS, washed and resuspended in the appropriate growth medium, counted in a haemocytometer and an aliquot replated at the indicated densities in $25 \mathrm{~cm}^{2}$ Corning T-flasks containing $1 \times 10^{5}$ irradiated fibroblasts as feeder layers. Cumulative cell numbers were estimated as if all cells had been replated at every passage.

Cultures were maintained at $37^{\circ} \mathrm{C}$ in a humidified $7 \% \mathrm{CO}^{2}$ in air atmosphere. The medium was changed every 2 or 3 days and the cells passaged every week.

Extraction of DNA. Harvested cells were disrupted in $0.5 \%$ SDS-60 mm Tris- $20 \mathrm{~mm}$ 
EDTA (pH 8.4) by freezing, thawing and homogenisation. The lysate was incubated with proteinase $\mathrm{K}(100 \mu \mathrm{g} / \mathrm{ml})$ for $3 \mathrm{~h}$ at $37^{\circ} \mathrm{C}$ and extracted with an equal volume of $1: 1(\mathrm{v} / \mathrm{v})$ phenol : chloroform mixture. The interface was re-extracted with SDS/Tris/EDTA and the aqueous extracts combined and dialysed against 3 changes of $10 \mathrm{~mm}$ Tris $-1 \mathrm{mM}$ EDTA (pH 7.5). The dialysed extract was incubated with heat treated RNAase $(50 \mu \mathrm{g} / \mathrm{ml})$ for $1 \mathrm{~h}$ at $37^{\circ} \mathrm{C}$. The mixture was re-extracted with phenol/chloroform and dialysed as above, ethanol-precipitated several times, washed with $70 \%$ ethanol, dried and redissolved in Tris/EDTA.

Estimation of DNA methylation. DNA samples were digested with endonucleases HpaII and MspI. To check that digestion was complete aliquot samples were incubated with PBR 322 DNA, submitted to electrophoresis on $7 \%$ agarose, containing ethidium bromide, gels and examined under UV light. After complete digestion, DNA was end labelled with ${ }^{32} \mathrm{P}$-dCTP by the Klenhoff fragment of DNA polymerase. After labelling the DNA was precipitated several times, washed with $70 \%$ alcohol, dried and redissolved in Tris/EDTA. The samples were then submitted to electrophoresis on $5 \%$ agarose gels and the gels sliced into $2 \mathrm{~mm}$ sections, counted by Cerenkhov radiation and the radioactivity of each fraction plotted as a percentage of the total.

Chemicals. DME powdered formulation was from Gibco, calcium free DME from Flow Laboratories, MCDB 151, foetal calf serum and streptomycin from Commonwealth Serum Laboratories, Trypsin-Serva Biochemicals. PBR 322 DNA, HpaII and MspI endonucleases were from PL Biochemicals and Chelex 100 mesh size 100-200 was from Biorad Pharmaceuticals. Epidermal Growth Factor (EGF) was from Collaborative Research and cholera toxin and hydrocortisone from Sigma, Proteinase K from Merck, RNAase from Worthington Biochemicals, Klenhoff fragment of DNA polymerase was from BohreingerManhoff and ${ }^{32} \mathrm{P}$-dCTP $5 \mathrm{mCi} / \mathrm{ml}-1800 \mathrm{Ci} / \mathrm{mmole}$ was from Bresa.

\section{RESULTS}

Figure 1 shows the morphology of human keratinocytes grown in medium containing high $(1.8 \mathrm{mM})(\mathrm{A})$ or low $(0.015 \mathrm{mM})(\mathrm{B})$ calcium. Cells grown in low calcium medium (Fig. 1B) retain a very flattened morphology with a regular polygonal shape and relatively clear cytoplasm. The cells continue to grow as a monolayer never assuming the stratified differentiated appearance of cells grown in high calcium medium. Cells grown in high calcium medium (Fig. 1A) stratify, become densely packed and possess cytoplasmic granules.

Cells derived from the same primary culture demonstrate different replicative capacity depending upon which growth medium is employed (Fig. 2). Cells grown in the low calcium medium undergo $35-40$ population doublings over $16-17$ passages while cells grown in the high calcium medium ceased proliferation and die after 20 population doublings over 7 passages. Death is arbitrarily defined when there is insufficient cells after one week of growth to reseed at $3 \times 10^{5}$ cells and the experiment was terminated at this point.

More importantly however, if cells are switched from one growth condition to the other, the fate of the cell population is reversed. Figure 3 plots the cell number at passage against passage number and demonstrates that for cells grown in high calcium medium, limitation of proliferation begins after 3-4 passages and the population dies after 7 passages whereas cells derived from the same primary culture grown in low calcium medium, continue to grow and divide. When cells are trans- 


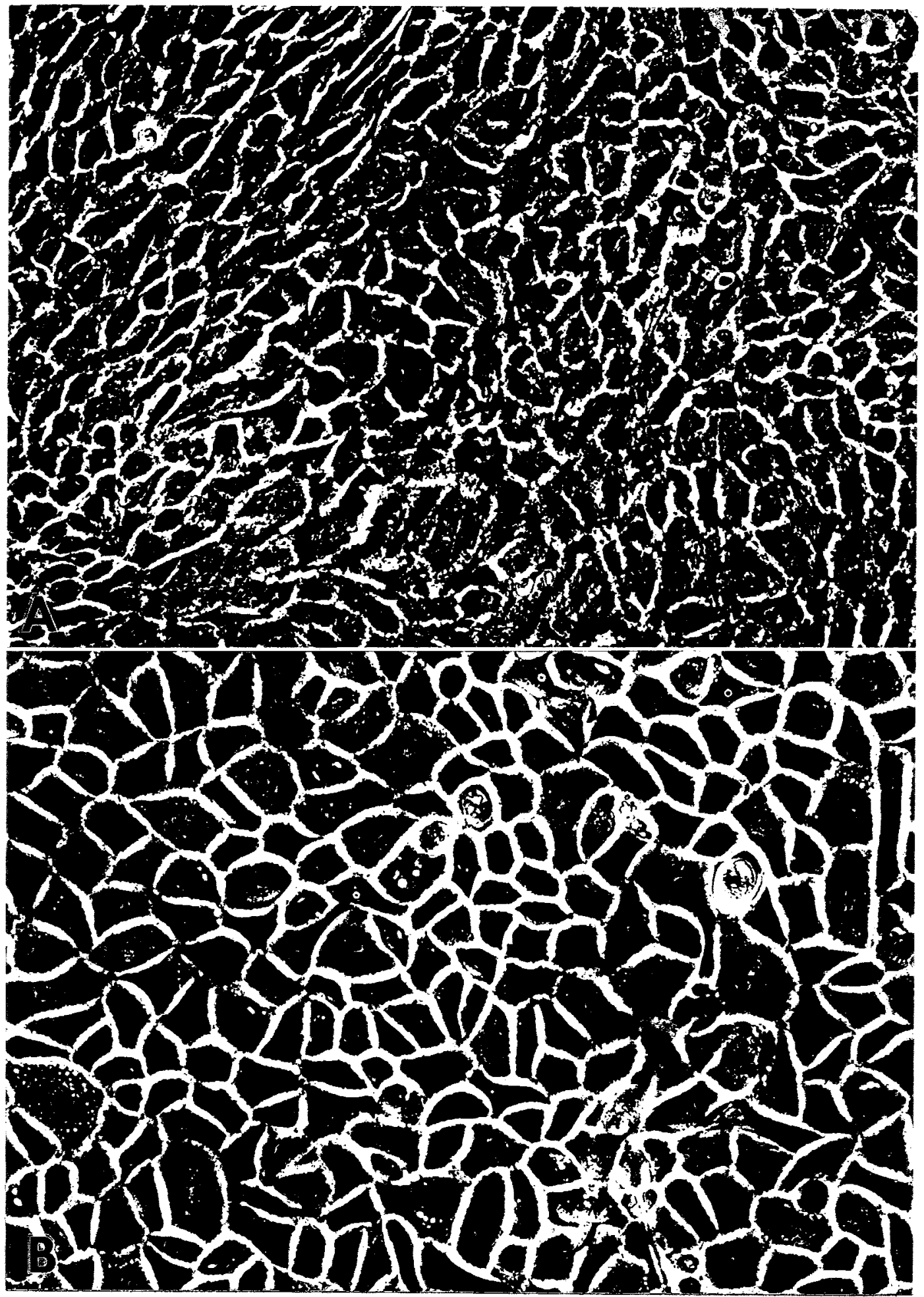




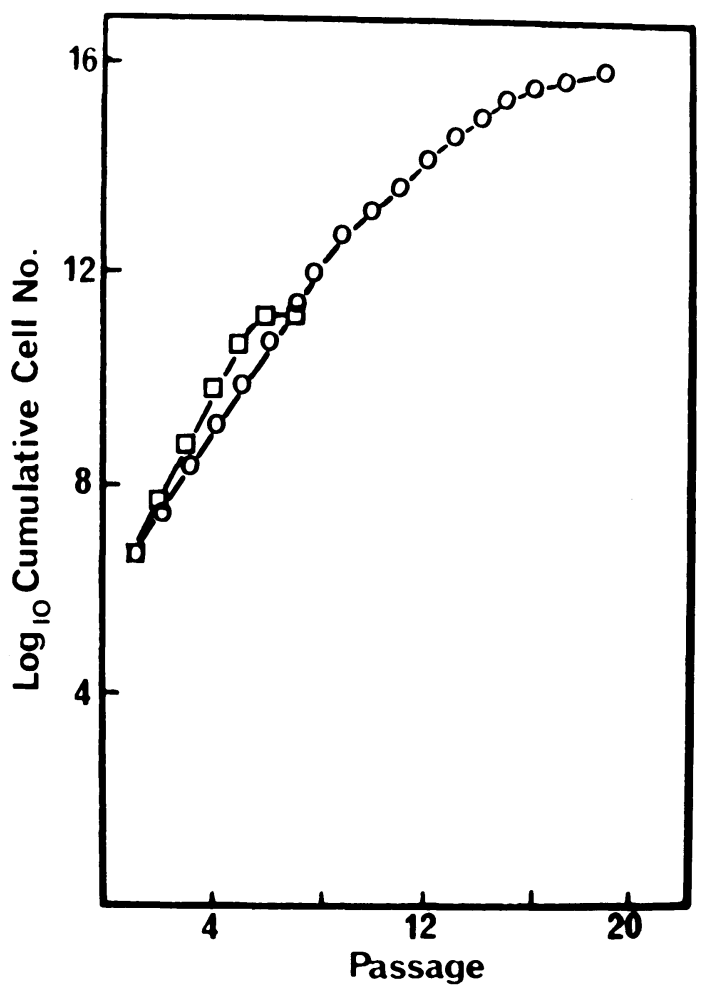

Fig. 2. Population growth curves of human keratinocytes in $(\square-\square)$ high calcium and $(\bigcirc-\bigcirc)$ low calcium medium as described in Fig. 1. The cells were passaged by trypsinization after washing with EDTA every 7 days and $3 \times 10^{5}$ cells reseeded into T-25 Corning flasks.

ferred from low calcium conditions to high calcium conditions they immediately limit proliferation and die within a few passages. On the other hand, when a population of cells that was destined to cease proliferation in high calcium growth conditions was transferred to low calcium conditions it recovered and continued to grow and divide. These populations survived for a similar duration as those maintained solely in the low calcium medium (results not shown).

The level of DNA methylation in these cells was measured as a function of the passage number by digestion of isolated DNA with the endonucleases HpaII and MspI. Both of these enzymes cut DNA at the same site but HpaII is inhibited by methylation at the internal $\mathrm{C}$ residue $(34,30)$. This method does not give an absolute measure of DNA methylation but a decrease in methylation can be seen in HpaII digests by a decrease in the proportion of counts in the high molecular weight region of the gel with a concomitant rise in the proportion of counts in the lower molecular weight range.

DNA samples from high calcium cultures at passages 2, 4 and 5 were examined

Fig. 1. Photomicrographs (phase contrast $\times 300$ ) of human keratinocytes cultured in (A) DME, $10 \%$ FCS supplemented with cholera toxin, hydrocortisone and epidermal growth factor (high calcium) and (B) $1: 1(\mathrm{v} / \mathrm{v})$ mixture of calcium free DME and MCDB 151 supplemented with $10 \%$ chelex treated FCS, cholera toxin, hydrocortisone and epidermal growth factor (low calcium). 


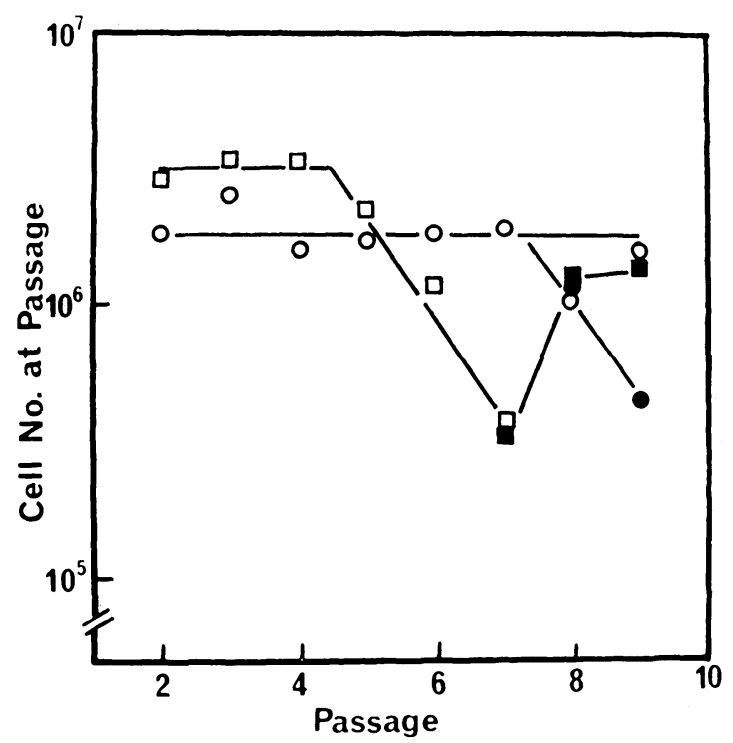

Fig. 3. The fate of cell populations growing in $(\square-\square)$ high calcium medium, $(\bigcirc-\bigcirc)$ low calcium medium, ( $\square-\mathbf{-})$ high calcium medium switched to low calcium medium at passage 6 and (-) low calcium medium switched to high calcium medium at passage 7 . The cells were passaged by trypsinization after washing with EDTA every 7 days and $3 \times 10^{5}$ cells reseeded into T-25 Corning flasks.
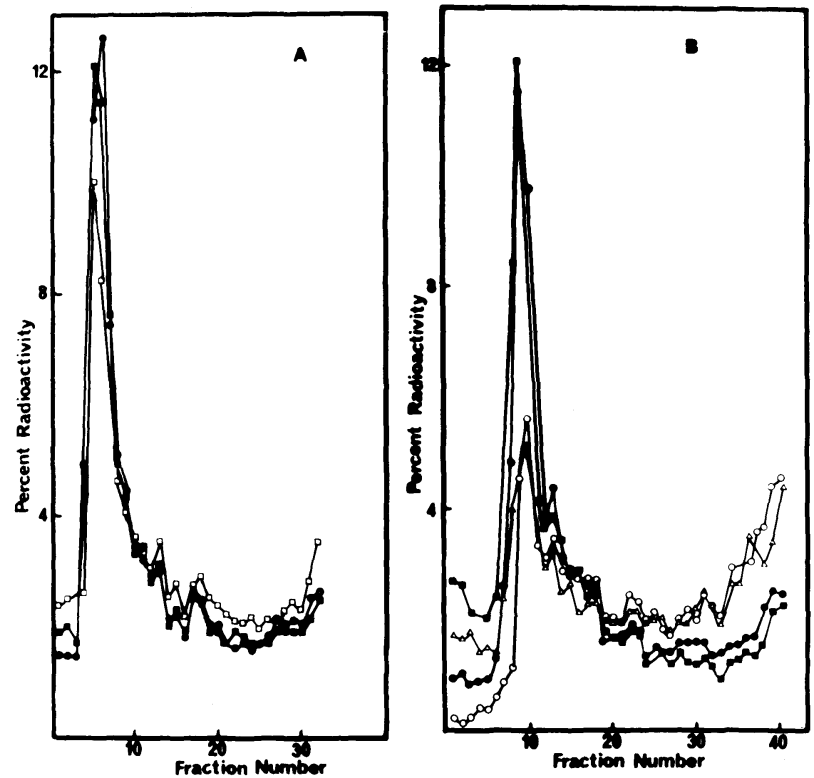

Fig. 4. Molecular weight distribution from agarose electrophoresis gels of ${ }^{32} \mathrm{P}$ end labelled fragments of HApAII digests of DNA from (A) high calcium cells at passage (-๑) 2 , ( $\square-\square) 4$ and $(\square-\square) 5$ and (B) low calcium cells at passage $(\bullet-)) 2,(\square-\square) 4$, (○—○) 8 and $(\triangle \longrightarrow \triangle) 16$. 
(Fig. 4A). The results show a slight decrease in DNA methylation of cells from passage 5. In low calcium growth conditions DNA from cells at passages 2, 4, 8 and 16 was examined. The DNA from cells at passage 8 and 16 had a significantly lower degree of methylation than DNA from cells at the earlier passages.

\section{DISCUSSION}

Fibroblasts in culture have been shown to have a finite capacity for growth which is brought about by senescence of the population. In the keratinocyte system, under investigation here, there are two reasons for cessation of growth. In high calcium growth conditions, continued proliferation is limited by terminal differentiation (9). In low calcium medium the cells have an extended proliferative capacity however, eventually, they senesce and the culture has a finite growth period comparable to the "Hayflick limit". Thus we have demonstrated, (i) that the calcium concentration of the growth medium significantly affects the growth period in vitro of human keratinocyte cultures derived from the same primary culture and (ii) that keratinocytes grown in low calcium growth conditions are similar to fibroblasts and other differentiated somatic cells including glial cells, lymphocytes, endothelial and adrenal cells (12) in having a finite lifespan in vitro.

That the calcium ion concentration affects the differentiation and growth period of keratinocytes in vitro raises interesting speculation on the local control of both differentiation and ageing in vivo. It has been shown that the $\mathrm{Ca}^{++}$content of skin varies significantly. The basal layer, which contains the proliferative cells, has an extremely low $\mathrm{Ca}^{++}$content while the upper layer, which contains differentiating and differentiated cells, has a 20 fold increase in $\mathrm{Ca}^{++}$content (7). It would be interesting to determine if the $\mathrm{Ca}^{++}$level of these layers changed with age. Accumulation of cellular calcium has been discussed as a factor in ageing (33) and the susceptibility of cardiac myocytes to calcium induced death has been shown to be age dependent (4). Shapiro et al. have demonstrated premature senescence in cultured skin fibroblasts from subjects with cystic-fibrosis (27) although Holliday has reported that two out of four fibroblast cultures from cystic-fibrosis patients had longer lifespans than controls (personal communication). Increased sweat electrolytes is characteristic of the disease and has also been linked with ageing (27) whilst more specifically the intracellular $\mathrm{Ca}^{++}$pool size is greater by about $30 \%$ in skin fibroblasts from cysticfibrosis sufferers and carriers when compared to those obtained from normal donors (26).

When cultures were switched between the growth conditions the fate of the cell populations was reversed. These results are consistent with the observation that cells will differentiate in high $\mathrm{Ca}^{++}$growth conditions and continue to proliferate until senescence in low $\mathrm{Ca}^{++}$growth conditions. It appears from our results that a proportion of keratinocytes growing in low calcium growth conditions may be already committed to differentiate because of the rapid limitation in growth observed when cells were switched from low calcium growth conditions to high calcium growth conditions. Previous measurement of the proportion of committed cells, as estimated by the production of cornified envelopes after exposure to the $\mathrm{Ca}^{++}$ionophore $\mathrm{X} 537 \mathrm{~A}$, indicated a level of $30 \%$ for cells growing in low calcium culture conditions compared to $65 \%$ for cells in high calcium culture conditions (23). Figures as high as $55 \%$ have recently been reported for cornified envelope production of human 
keratinocytes growing in low calcium growth conditions (2). These results with keratinocyte senescence in low calcium growth conditions may have some relevance to the commitment theory of cellular ageing (17) but it is questionable whether "commitment" to differentiate in the epithelial keratinocyte system is equivalent to "commitment" of a subpopulation of fibroblastic cells to a finite number of population doublings as envisaged in the Kirkwood-Holliday model.

Our results demonstrate that decreases in the level of DNA methylation occur with time in cultured human keratinocytes but they do not establish whether this loss of methyl groups is related to the number of cell divisions. There has been recent discussion on the role of methylation in gene expression with demethylation of DNA sequences being implicated in the transcription and expression of genes which would remain unexpressed in the methylated state (see reviews 5, 15). In regard to ageing, the level of DNA methylation in human diploid fibroblasts has been shown to decrease with age in culture in two out of three strains tested (28) and has also been demonstrated to decrease with age in culture in fibroblasts isolated from mice, hamsters and humans but not in "immortal" mouse cell lines (36). There is some evidence that DNA methylation declines with age in vivo. Romanov and Vanyushin have demonstrated decreases in the methylation of reiterated, but not unique, sequences in cattle with ageing (24) whilst Mays-Hoopes et al. have observed hypomethylation of specific moderately repeated sequences of the mouse liver genome with age (18). It is known that reiterated DNA sequences tend to have a higher proportion of methylated sites than other areas of the genome (21) and experiments are under way to look at keratinocyte reiterated DNA sequences in this regard.

It has recently been shown that a single treatment of early passage cells with the base analogue 5-azacytidine, which is known to reduce the level of 5-methyl cytosine in DNA, has a profound life shortening effect on populations of human fibroblasts (14). These results might suggest a direct role of methylation in ageing and Holliday, in reviewing these experiments, concluded "that the stochastic loss of epigenetic controls of gene expression may be an important component in the ageing process" (12).

In summary then we have demonstrated that the $\mathrm{Ca}^{++}$concentration of the medium significantly affects the growth period in vitro of human keratinocyte cultures derived from the same primary culture and that the fate of the cell populations can be reversed by changing the growth conditions. Keratinocytes grown in low calcium conditions are similar to fibroblasts and other differentiated somatic cells in having a finite lifespan in vitro.

We have demonstrated a decrease in DNA methylation of human keratinocytes in culture which is associated with senescence but does not appear to be associated with differentiation. Whether or not this change can be traced to specific genes or reiterated DNA sequences controlling genes which may be related to ageing will have to await further study.

\section{REFERENCES}

1. AdAm, G. Population-dynamical model of cell density dependent growth regulation and aging of fibroblasts in vitro. J. Theor. Biol. 84, 233-257, 1980

2. Boonstra, J., S.W. DelaAt and M. Ponec. Epidermal growth factor receptor expression 
related to differentiation capacity in normal and transformed keratinocytes. Exp. Cell Res. 161, 421-433, 1985

3. Breitkreutz, D., A. Bohnert, E. Herzmann, P.E. Bowden, P. Boukamp and N.E. Fusenig. Differentiation specific functions in cultured and transplanted mouse keratinocytes. Diff. 26, 154-169, 1984

4. Chizzonite, R.A. and R. ZAK. Calcium induced cell death: susceptibility of cardiac myocytes is age dependent. Science 213, 1508-1511, 1981

5. Doerfler, W. DNA methylation and gene activity. Ann. Rev. Biochem. 52, 93-124, 1983

6. Erlich, M., M.A. Gama-Sosa, L.H. Huang, R.M. Midgett, K.C. Lo, R.A. McCune and C. Gerke. Amount and distribution of 5 methyl cytosine in human DNA from different types of tissues or cells. Nucl. Acid Res. 10, 2709-2721, 1982

7. Forslind, B., G.M. Roomans, L.E. Carlsson, K.G. Malmquist and K.R. Akselsson. Elemental analysis on freeze dried sections of human skin: studies by electron microprobe and particle induced X-ray emission analysis. Scan. Electron Microsc. 2, 755-759, 1984

8. FuCHS, E. and H. Green. Changes in keratin gene expression during terminal differentiation of the keratinocyte. Cell 19, 1033-1042, 1980

9. Green, H. Terminal differentiation of cultured human epidermal cells. Cell 11, 405-416, 1977

10. Hayflick, L. Cell senescence and cell differentiation in vitro. In; Ageing and Development. ed. H. Bredt and J.W. Rohen, vol. 4, Schatlaur Verlag, Stuttgart, pp. 1-15, 1972

11. Hennings, H., D. Michael, C. Cheng, P. Steinert, K. Holbrook and S. Yuspa. Calcium regulation of growth and differentiation of mouse epidermal cells in culture. Cell 19, 245-254, 1980

12. Holliday, R. Testing molecular theories of cellular ageing. In; Thresholds on Ageing: The 1984 Sandoz Lectures in Gerontology. ed. by M. Bergeber, E. Ermini, H. B. Stahelin. Academic Press, New York, 1985

13. Holliday, R. Genes Proteins and Cellular Ageing. ed. by R. Holliday. Von Nostrand and Reinhold Co., New York, 1985

14. Holliday, R. The significance of DNA methylation. In; The Molecular Biology of Ageing. ed. by Woodhead A.D., Blackett, A.D., Hollaender, A., pp. 269-283. Plenum Press, New York, 1985

15. JAENISCH, R. and D. JAHNER. Methylation expression and chromosomal position of genes in mammals. Biochim. Biophys. Acta. 782, 1-9, 1984

16. Jones, R.B. and J.R. Smith. A stochastic model of cellular senescence. II Concordance with experimental data. J. Theor. Biol. 96, 443-460, 1982

17. Kirkwood, L.B.L. and R. Holliday. Commitment to senescence: a model for the finite and infinite growth of diploid and transformed human fibroblasts in culture. J. Theor. Biol. 53, 481-496, 1975

18. Mays-Hoopes, L.L., A. Brown and R.C.C. Huang. Methylation and rearrangement of mouse intra cisternal A particle genes in development, ageing and myeloma. Mol. Cell Biol. 3, 1371-1380, 1983

19. Orgel, L.E. The maintenance of the accuracy of protein synthesis and its relevance to ageing. Proc. Natl. Acad. Sci. U.S.A. 49, 517-521, 1963

20. PeEL, D.M. and R.G. HAM. Clonal growth of human keratinocytes with small amounts of dialysed serum. In Vitro 16, 526-538, 1980

21. RAZIN, A. and A.D. RigGs. DNA methylation and gene function. Science 210, 604-610, 1980

22. Rheinwald, J.G. and H. Green. Serial cultivation of strains of human epidermal keratinocytes: the formation of keratinizing colonies from single cells. Cell 6, 33-44, 1975

23. Rockwell, G.A. and A. Sibatani. The role of $\mathrm{Ca}^{++}$in the commitment of epidermal keratinocytes. Cancer Forum 6, 243-245, 1982

24. Romanov, G.A. and B.F. Vanyushin. Methylation of reiterated sequences in mammalian DNAs. Effects of the tissue type, age, malignancy and hormonal induction. Biochim. Biophys. Acta 653, 204-218, 1981

25. SChneider, E.L. and J.R. Smith. The relationship of in vitro studies to in vivo human aging. 
Int. Rev. Cytol. 69, 261-270, 1981

26. Shapiro, B.L., R.J. Feigal, N.J. Laible, M.H. Biros and W.J. Warwick. Doubling time, alpha amino isobutyrate transport and calcium exchange in cultured fibroblasts from cystic fibrosis and control subjects. Clin. Chim. Acta 82, 125-132, 1978

27. Shapiro, B.L., L.F. LAM and L.H. Fast. Premature senescence in cultured skin fibroblasts from subjects with cystic fibrosis. Science 203, 1251-1253, 1979

28. Shmookler Reis, R.J. and S. GoldStein. Loss of reiterated DNA sequences during serial passage of human diploid fibroblasts. Cell 21, 739-749, 1980

29. Shmookler Reis, R.J., C.K. Lumpkin, J.R. McGill, K.T. Riabouol and S. Goldstein. Genome alteration during in vitro and in vivo ageing: amplification of extrachromosomal circular DNA molecules containing a chromosomal sequence of variable repeat frequency. Cold Spring Harb. Symp. on Quant Biol. 47, 1135-1139, 1983

30. Singer, J., J. Roberts-Ems and A.D. Riggs. Methylation of mouse liver DNA studied by means of the restriction enzymes MspI and HpaII. Science 203, 1019-1021, 1979

31. Strehler, B., M.-P. Chang and L.K. Johnson. Loss of hybridizable ribosomal DNA from human post mitotic tissues during aging. I Age dependent loss in human myocardium. Mech. of Ageing and Dev. 11, 371-378, 1979

32. Strehler, B. and M.-P. Chang. Loss of hybridizable ribosomal DNA from human post mitotic tissues during aging. II Age dependent loss in human cerebral cortex-hippocampal and somato-sensory cortex comparison. Mech. of Ageing and Dev. 11, 379-382, 1979

33. Strehler, B.L. In Time Cells and Ageing. ed. by B.L. Strehler, 2nd ed, Academic Press, New York, 1977

34. Waalwijk, C. and R.A. Flavell. MspI an isoschizomer of HpaII which cleaves both unmethvlated and methylated HpalI sites. Nucl. Acid Res. 5, 3231-3236, 1978

35. Weisman-Shomer, P., A. Kaftory and M. Fry. Replicative activity of isolated chromatin from proliferating and quiescent early passage and aging cultured mouse cells. J. Cell Physiol. 101, 219-228, 1979

36. WiLson, V.L. and P.A. Jones. DNA methylation decreases in aging but not in immortal cell lines. Science 220, 1055-1057, 1983

(Received for publication, August 22, 1987) 